thus to one whose investigations have been confined to those species growing in the temperate zones, Cinchona furnishes splendid opportunity for the extension of his work to such allied tropical species.

A tropical rain-forest presents peculiar conditions. The plants do not show the marked periodicity characteristic of colder and dryer regions. Where the temperature and rainfall are so nearly constant at all times of the year as at Cinchona, one is likely to find all of the stages in the life history of a species on almost any single day, and conditions are favorable for collecting the year around. In the plants of a tropical rain-forest, moreover, there is much less cutin, fewer hairs, etc., to interfere with the penetration of fixing solutions, and hence there is the probability of better fixation. That such is not in all cases true is evidenced through the impermeability of the walls of fern sporangia, and the hairiness of the leaves of the Gymnogrammeæ may be as striking here as elsewhere.

To the cytological collector a compound microscope is an absolute necessity; and such a permanent station as that at Cinchona, therefore, seems to be the only solution to the accessibility of such regions. The buildings at Cinchona, including two cottages, a two-room laboratory, the drying house, the dark room, the greenhouses and the garden, were all in good condition when I left there in December last. Through the kind offices of Mr. William Harris at Hope Gardens servants were made available, and one's personal needs adequately supplied. The space is sufficient for a number of investigators at one time, and life there is very pleasant indeed.

C. H. FARR

Columbia UNIVERSITY

\section{EXPERIMENTAL WORK AT CINCHONA}

The portions of the Blue Mountains which are accessible from Cinchona, at both higher and lower altitudes, exhibit a diversity of vegetation in correlation with the widely differing temperature and moisture conditions, and also a vertical diversity from floor to canopy within the rain-forest itself. Ample opportunity is thus offered for the investigation of the physical environment in relation to the local and general distribution of plants. A wide range of plant material is available for the study of . general physiological behavior as well as for the special types of activity characteristic of rain-forest plants. The fundamental processes of plants, as carried on under extremely humid conditions, and the influence of the character and rate of these processes upon the growth, distribution and periodic phenomena of the hygrophytic vegetation offer a rich field for future work at Cinchona. The gardens, greenhouses and various outbuildings afford opportunity for propagating plants and for placing them under a variety of experimental conditions. The nearness of an extensive tract of virgin forest is also a valuable asset for physiological as well as ecological work. The excellent trails, the easy means of communication and supply, the presence of a guide with a knowledge of the local flora, and the very healthful living conditions combine to make Cinchona an extremely useful station for those who may wish to carry on more or less prolonged investigations in the problems of the semi-torrid and humid tropics.

The Desert Laboratory

\section{Forrest Shreve}

\section{UNIVERSITY AND INDUSTRY 1}

1. This Committee was appointed at the April, 1916, meeting to consider the papers presented at the meetings in November and December, 1915, and in April, 1916, and to report at the June, 1916, meeting; this report to embody the findings, conclusions and recommendations of this committee based upon the foregoing material, supplemented by such other as this committee was able to consider.

2. Your committee was divided into three subcommittees to examine the above subjectmatter from three different points of view: Firstly, that of the university; secondly, that of the industries, and thirdly, that of the consulting chemists. Each of these subcommittees reached its conclusions separately and these conclusions were then submitted in writing to the full committee. The work of the whole committee is given in the following under

1 Report of a committee of the New York Section, American Chemical Society. 
three headings, namely: Findings, Conclusions and Recommendations.

\section{FINDINGS}

(a) Research is the source of all added knowledge.

(b) The universities are properly institutions of research.

(c) The proper development of university research requires unlimited and unrestricted publicity as to all its activities and results.

(d) Not all research activities of the industries can be published and it is only in such cases where publicity is compatible with industrial progress, that full cooperation between the universities and the industries can be effected.

(e) When a faculty-member as an individual works in conjunction with an individual industry and the results of that work are kept secret, that is not that cooperation between universities and industries which this committee is considering.

(f) Industrial or similar fellowships when founded by industrials or groups of industrials, coupled with publicity of the results, are effective modes of cooperation; the effectiveness of these fellowships diminishes as the number of contributing industrials decreases and the liberty to publish is restricted.

(g) In the case of problems of the industries where the results shall be held exclusive or secret or subject to patent, no general solution can be offered, but in each such case the individual industrial and the individual faculty-member or the individual institution must work out the best plan under the given set of conditions.

(h) No matter how efficiently the university may train its men, the industries that take up such men must be prepared to expend considerable of their own time, effort and money in training such men for the specific work before them.

(i) The tuition and fees paid by students cover only a small part of the cost of their education at the universities.

(j) Apprenticeship of chemists during summer vacations in the industries is not in gen- eral feasible, and in general is limited to routine experience in the analytical laboratory and not in the manufacturing plant proper.

(k) Scientific problems and the scientific side of technical problems are proper subjects for university treatment and investigation; the bringing of the university professor into the industries by having him examine the problem in the plant and determine the scientific aspect of the problem, and the pursuit of that problem in the university, is a promising point of entry for increased cooperation.

\section{CONCLUSIONS}

I. Cooperation, such as has been had heretofore, between associations of industries and institutions of learning for the solution of scientific problems or the scientific side of industrial problems, which are common to such specific industries, and the appropriate publication of the results of such investigations, has been productive of great public good, and the greatest immediate prospect for expansion of cooperation between universities and industries lies in coordinated effort along the above lines.

II. There are industrial problems not common to any group or number of plants and which can not properly be published, and these are, therefore, not adapted to university treatment; problems of this kind in the course of time do become common to the entire industries; to increase cooperation in this class of problems it is needful to accelerate the transfer of problems of this class to problems of the preceding class.

III. In order that there may be as little duplication of effort and labor as possible, and the greatest acceleration of cooperation, a permanent central committee should be created and appointed by representatives of the universities and the industries, and such committee should study opportunities and make public recommendations for cooperation along the lines laid down in these conclusions.

IV. Cooperation between universities and industries as to uniform requirements in the fundamentals of instruction seems possible, feasible and mutually profitable. 
V. Such universities as aim to produce technical men should equip them with a working acquaintance with the fundamental types of machinery likely to be used in actual practise.

VI. In order to increase opportunity for research on the part of qualified faculty-members, relief from routine and administrative work within the university should be encouraged and executed to its reasonable limit.

VII. Our universities have a training capacity for branches of industry not now existent in this country; such unexploited training opportunities should be published by the universities to the end that our industrials and others might take up the advisability of creating such non-existent industry.

VIII. The industries can stimulate research by publishing such specific problems as may be common to the industry and yet not of sufficient importance to the industry to undertake their solution directly; such problems would afford valuable training for students and give them live material upon which to work.

IX. The industries, through associations and otherwise, when submitting problems for research, would facilitate the work if they were to make reasonable provision for the financial reimbursement of the university for its expenditure of time, effort and material, and thereafter provide for suitable stimulus and encouragement for expansion of cooperative effort, such as endowments, fellowships and the like.

\section{RECOMMENDATION}

In view of the foregoing, this committee is unanimous in recommending that the American Chemical Society take the initiative in creating the committee suggested in Conclusion III.

Respectfully submitted,

Charles Baskerville, Chairman

W. S. Allen,

Virail Coblentz,

Geo. A. Hulett,

E. G. Love,

Russell W. Moore,

Maximilian Tooh,

J. C. OLSEN,

F. G. WIECHMANN

\section{DR. UGO SCHIFF}

THE recent death of Dr. Ugo Schiff, professor of chemistry in the Royal Institute of Florence, recalls to mind that historical meeting of chemists which convened in Karlsruhe in 1860. The classical work of Stas on atomic weights published about this date had caused much discussion as to the real significance of these constants. There was, however, no uniformity in regard to the choice of equivalents, with the result that great confusion existed in the selection of formulas of compounds. Thus the formula for even so simple a substance as water will be found in the writings of the chemists of this period designated variously as $\mathrm{H}_{2} \mathrm{O}, \mathrm{H}_{2} \mathrm{O}_{2}$ and $\mathrm{HO}$, while the more complex compounds were sometimes represented by a score or more of different formulas. In order to discuss this unfortunate situation and with the hope that some system might be brought out of the chaotic condition, Kekule and a few of his associates called a meeting of the great chemists of Europe: This meeting convened in Karlsruhe in 1860. It was here, after much discussion, that Cannizzaro delivered that now justly renowned address in which he pointed out that all confusion would disappear if we but accept in its entirety the hypothesis advanced by his fellow countrymen, Avogadro and Ampere. The address was published in pamphlet form and distributed among the chemists present. The effect of the address may be judged from the following quotation ${ }^{1}$ from Lothar Meyer:

I too got a copy which I put in my pocket to read on my home journey. I read it again and again and was astonished at the light which the writing threw on the most important points at issue. The scales fell from my eyes, doubt vanished and a sense of the calmest certainty took its place.

For a number of years preceding his death Schiff was the only living representative of that remarkable body of men who attended this conference. The mention of his name to any of the chemists in Europe was almost certain to bring the reply that he was the only

1 Armitage, "A History of Chemistry." 